WellBeing International

WBI Studies Repository

1981

\title{
A Function of the Subelytral Chamber of Tenebrionid Beetles
}

Con Slobodchikoff

Northern Arizona University

Kim Wisman

Northern Arizona University

Follow this and additional works at: https://www.wellbeingintlstudiesrepository.org/ento

Part of the Animal Studies Commons, Entomology Commons, and the Zoology Commons

\section{Recommended Citation}

Slobodchikoff, C. N., \& WISMANN, K. (1981). A function of the subelytral chamber of tenebrionid beetles. Journal of Experimental Biology, 90(1), 109-114.

This material is brought to you for free and open access by WellBeing International. It has been accepted for inclusion by an authorized administrator of the WBI Studies Repository. For more information, please contact wbisr-info@wellbeingintl.org.

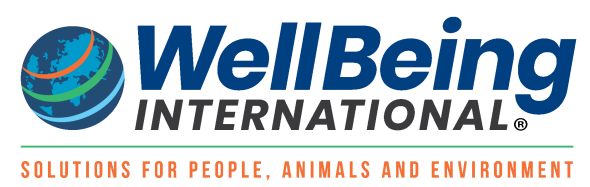




\title{
A FUNCTION OF THE SUBELYTRAL CHAMBER OF TENEBRIONID BEETLES
}

\author{
By C. N. SLOBODCHIKOFF AND KIM WISMANN \\ Department of Biological Sciences, Northern Arizona University, Flagstaff $860 \mathrm{I}$ I
}

(Received I I February 1980)

\begin{abstract}
SUMM A R Y
I. The subelytral chamber is an air space between the elytra and the dorsum of the abdomen of some Tenebrionid beetles. Postulated functions for the subelytral chamber have been a reduction of transpiratory water loss and a thermal buffer for heat flow from the elytra to the abdomen.

2. We show that there is a significant correlation between water loss and the depth of the subelytral chamber.

3. This implies that the chamber may be a structure that permits the rapid expansion of the abdomen, providing the beetles with a mechanism by which they can quickly drink large quantities of water from an ephemeral source such as a rain puddle. As the beetles drink, the abdomen greatly expands, and the chamber shrinks.
\end{abstract}

\section{INTRODUCTION}

Some beetle species in the family Tenebrionidae are flightless inhabitants of arid or semi-arid regions of the world. These species have vestigial wings, and the elytra are fused into a carapace that encloses the dorsum of the abdomen. Between the fused elytra and the dorsum of the abdomen is often found an air-filled space, termed the subelytral chamber.

The function of the subelytral chamber has been the subject of some speculation. Cloudsley-Thompson ( 1964 ) suggested that the function of the subelytral chamber was to reduce transpiratory water loss. Cloudsley-Thompson's results were substantiated by Ahearn \& Hadley (1969) and Ahearn (1970); when the elytra are removed, exposing the subelytral chamber and the dorsum of the abdomen, the transpiratory rate of water loss increases. Edney (I97I) and Hadley (1972) suggest that since the subelytral chamber is filled with air, which is a poor conductor of heat, the subelytral chamber acts as a buffer zone, retarding the flow of heat from the elytra to the abdomen.

Since Tenebrionid beetles become abundant in the American Southwest at a time that coincides with the onset of the rainy season (Tanner \& Packham 1965), we formed the hypothesis that the subelytral chamber allows the abdomen to expand rapidly when the beetle drinks from a plentiful supply of water, such as a rain puddle. According to our hypothesis, a beetle would drink until the abdomen filled the hamber completely. The water would then be stored for a prolonged period of time. 
The depth of the subelytral chamber would gradually increase as the beetle lost water through various metabolic and physical processes and at the same time, the abdomen would shrink in size. When the beetle finds another supply of water, the chamber, according to this hypothesis, should once again shrink and disappear.

To test this hypothesis, we examined the water loss and subelytral depth of 100 Eleodes obscura Tenebrionids found in the higher Arizona deserts. Since water loss is inversely related to the percentage relative humidity, we tested our hypothesis under conditions of water deprivation at $0 \% \mathrm{RH}$ and $50 \% \mathrm{RH}$. The predictions derived from our hypothesis were the following: (I) water loss (as measured by total weight loss) should be negatively correlated to subelytral chamber depth; (2) the subelytral chamber depth should increase more rapidly during the course of the experiments at a relative humidity of $0 \%$ than at a relative humidity of $50 \%$.

\section{METHODS AND MATERIALS}

Only Eleodes obscura (Say) males were used in the experiments. Females were not used because of the problem arising from potential weight changes due to oviposition of a clutch of eggs. One hundred males were collected near Montezuma Well, Arizona, during the first two days of August, 1977. Once collected, the beetles were kept for 2-3 days in 15 by $30 \mathrm{~cm}$ plastic cages, 10 beetles to a cage. Each cage had a $\mathrm{I} \mathrm{cm}^{3}$ sponge, moistened daily with $10 \mathrm{ml}$ of water.

On 5 August 1977 the beetles were placed into $500 \mathrm{ml}$-capacity glass jars, one beetle per jar. The beetles were divided into two groups of 50 beetles each, the $\circ \%$ and the $50 \%$ relative humidity groups. Within each group, approximately half the beetles, chosen by a random number table, had a $2 \mathrm{~mm}^{2}$ hole cut into the right elytron, for the purpose of measuring the subelytral chamber depth. Twenty-five of the $50 \% \mathrm{RH}$ group and 26 of the $\circ \% \mathrm{RH}$ group were treated in the above manner. The remaining beetles in each group represented the controls, to test for possible increased water loss as a result of cutting through the elytron. The asymmetry in the size of the sub-groups resulted from a counting error.

The $50 \% \mathrm{RH}$ group was placed in an environmental chamber where temperature was a constant $25 \pm 0.5{ }^{\circ} \mathrm{C}$, and relative humidity (maintained by a Sovereign laboratory humidifier and controlled by a Honeywell $\mathrm{H}_{4} 6 \mathrm{~F}$ sensor) was $50 \pm 2 \%$, as measured by a Honeywell hygrothermograph. The $0 \% \mathrm{RH}$ group was placed in another environmental chamber at a temperature of $25 \pm 0.5^{\circ} \mathrm{C}$; air was circulated past Drierite crystals $\left(\mathrm{CaSO}_{4}\right)$ resulting in $\circ \% \mathrm{RH}$ as measured by a Honeywell hygrothermograph.

The beetles were weighed with a Mettler balance at the start of the experiment, then every $48 \mathrm{~h}$ for $\mathrm{I} 44 \mathrm{~h}$. They were weighed a final time at $156 \mathrm{~h}$. The subelytral chamber depth of the beetles was measured at the same time as they were weighed, using a I $\mathrm{mm} \times \mathrm{x} \mathrm{mm} \times 5 \mathrm{~cm}$ plastic ruler inscribed with lines every $0.2 \mathrm{~mm}$. 
Table I. $t$-Values of differences between mean weights of beetles with cut elytra and beetles with uncut elytra at different times. D.F. is the degrees of freedom, and N.S. stands for $P<0.05$

\begin{tabular}{|c|c|c|c|c|c|c|}
\hline \multirow[b]{2}{*}{ Time (h) } & \multicolumn{3}{|c|}{$0 \% \mathrm{RH}$} & \multicolumn{3}{|c|}{$50 \% \mathrm{RH}$} \\
\hline & t 8 cut -8 uncut & D.F. & Significance & $t \overline{\mathrm{x}}$ cut $-\overline{\mathrm{x}}$ uncut & D.F. & Significance \\
\hline 0 & 0.617 & 48 & N.s. & 0.5642 & 48 & N.s. \\
\hline 48 & 0.3229 & 48 & Pis. & 0.2725 & 48 & N.s. \\
\hline 96 & 0.3185 & 48 & N.s. & 0.1926 & 48 & N.s. \\
\hline I 44 & 0.3403 & 48 & N.8. & 0.1521 & 48 & N.s. \\
\hline
\end{tabular}

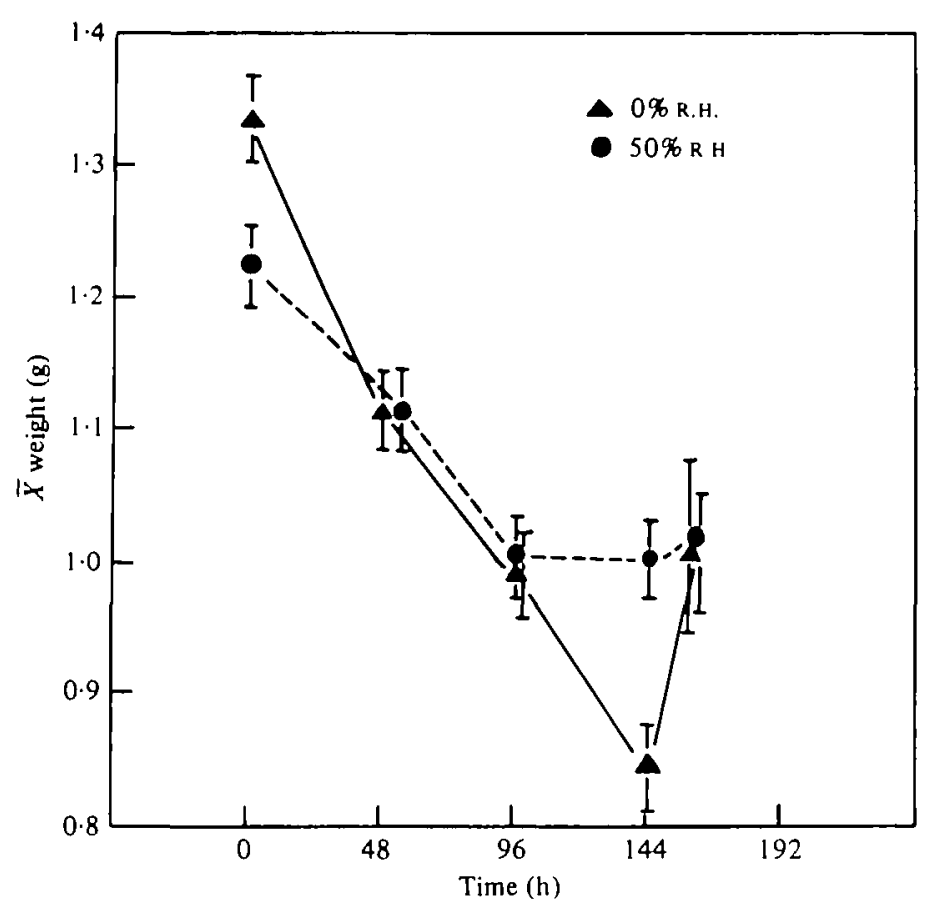

Fig. I. Mean weight loss as a function of the length of time of water deprivation. Solid line indicates $\circ \% \mathrm{RH}$ regime, and dotted line indicates $50 \% \mathrm{RH}$ regime. Vertical bars indicate one standard error on each side of the mean.

\section{RESULTS}

In both groups ( $0 \%$ and $50 \% \mathrm{RH}$ ), there were no significant differences in weight loss between the cut-elytron and uncut-elytron subgroups. Both subgroups lost weight similarly (Table $\mathrm{I}$ ). Thus, the experimental procedure of cutting a small hole in the elytron for the purpose of measuring the depth of the subelytral chamber did not significantly affect the weight loss by the beetles.

The $0 \%$ and the $50 \%$ groups both lost weight during water deprivation (Fig. I). Initial starting mean weights of the two groups proved to be significantly different $(t=3.049$, D.F. $=98, P<0.01$ ), either through chance or through some process af unconscious selection of beetles by size. At $48 \mathrm{~h}$, the mean weights of both groups Thowed no significant difference $(t=0.214$, D.F. $=98$, N.S. $)$. By $96 \mathrm{~h}$, however, the 


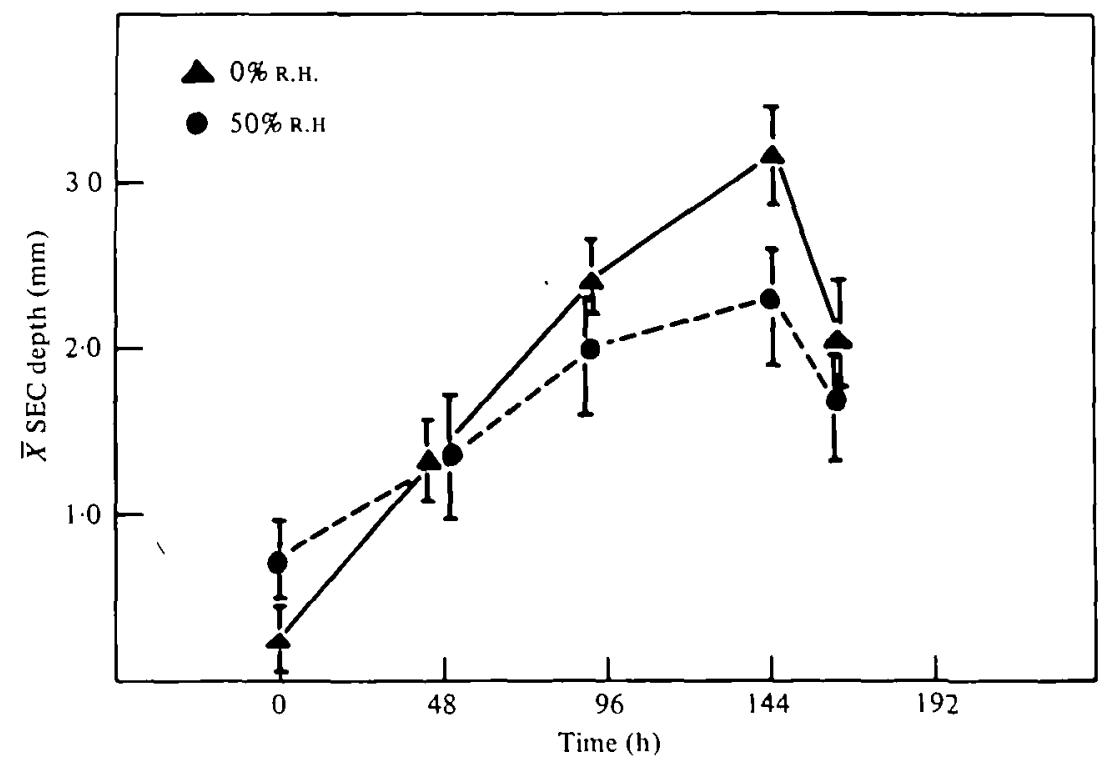

Fig. 2. Mean subelytral chamber depth as a function of the length of time of water deprivation. Solid line indicates $\circ \% \mathrm{RH}$ regime, and dotted line indicates $50 \% \mathrm{RH}$ regime. Vertical bars indicate one standard error on each side of the mean.

means were significantly different $(t=2.75 \mathrm{I}$, D.F. $=96, P<0.0 \mathrm{I})$, the $\circ \%$ RH group having lost more weight than the $50 \% \mathrm{RH}$ group. At this time, weight loss for the $50 \% \mathrm{RH}$ group appeared to stabilize, while the $\% \% \mathrm{RH}$ group continued to lose weight, until the mean weight difference at $\mathrm{I} 44 \mathrm{~h}$ was highly significant $(t=5.929$, D.F. $=76, P<0.001$ ). When both groups were given $5 \mathrm{ml}$ of water at $144 \mathrm{~h}$, both groups showed a weight gain when weighed at $156 \mathrm{~h}$. The $50 \% \mathrm{RH}$ group showed a relatively small gain, while the $\circ \% \mathrm{RH}$ group showed a relatively large gain, resulting in no significant difference between the mean weights of the two groups $(t=0.089$, D.F. $=34$, N.S. $)$.

Water deprivation was not continued for more than $144 \mathrm{~h}$ because of increasing mortality in the $\circ \% \mathrm{RH}$ group. By $96 \mathrm{~h}$, the $\circ \% \mathrm{RH}$ group had $4 \%$ mortality. By $\mathrm{I} 44 \mathrm{~h}$, the $\circ \% \mathrm{RH}$ group had $56 \%$ mortality. In contrast, none of the $50 \%$ group beetles died during the course of the experiment.

As the mean weights of the two groups decreased, the mean depth of the subelytral chamber increased (Fig. 2). Just as the mean weights of the two groups were significantly different at the start of the experiment, the mean depth of the subelytral chambers of the two groups started out being significantly different $(t=2 \cdot 158$, D.F. $=49, P<0.05)$. At $48 \mathrm{~h}$, there was no significant difference in mean depths $(t=0.003$, D.F. $=49$, N.S. $)$, nor was there a significant difference between the two groups at $96 \mathrm{~h}(t=1 \cdot 267$, D.F. $=49$, N.S. $)$. By I $44 \mathrm{~h}$, however, the difference between the mean depths of the chambers of the two groups was statistically significant $(t=3.284$, D.F. $=27, P<0.01)$. After the beetles were given water, the difference became non-significant $(t=I \cdot I I 6$, D.F. $=27$, N.S. $)$.

Regression analysis shows that weight and subelytral chamber depth are negativel correlated $(r=-0.546, N=222, P<0.01)$. The regression equation generated 
regressing weight (WT) on subelytral chamber depth (SEC) is as follows: $\mathrm{WT}_{1}=\mathrm{I} \cdot 270-0.546 \mathrm{SEC}_{1}$. This equation explains $29 \cdot 8 \%$ of the variance, which by analysis of variance is significant at $P<0.00 \mathrm{I}(F=93.38$; D.F. $=1,220)$. Thus, there is a significant negative relationship between weight of the beetle and depth of the beetle's subelytral chamber.

\section{DISCUSSION}

The results substantiate our initial predictions, that water loss is negatively correlated to subelytral chamber depth, and that the subelytral chamber depth increases more rapidly at lower relative humidity than at higher humidity. In both groups, the subelytral chamber depth increased, and the $\circ \% \mathrm{RH}$ group showed the fastest rate of increase.

When the beetles were given water at $\mathrm{I} 44 \mathrm{~h}$, the subelytral chamber depth did not decrease to the point where there was no measurable chamber present. Possible explanations include: ( $\mathrm{I}$ ) the amount of water was not sufficient to inflate the abdomen to the point where no measurable chamber was present; (2) the assimilation rate of water from the gut into the abdominal cavity is dependent on processes of osmoregulation of the haemolymph. Riddle, Crawford \& Zeitone (1976) have shown that a related beetle, Eleodes hispilabris, is able to regulate its haemolymph osmolality over a wide range of water loss. Such regulation of osmolality may set constraints on the rate at which water could be assimilated into the haemolymph.

Storage of water may be particularly important for Tenebrionid beetles, since many produce defensive secretions which are sprayed or exuded when the beetle is attacked by a predator (Tschinkel, 1975). If a beetle such as Eleodes longicollis, which normally produces defensive secretions, is deprived of water, the beetle becomes incapable of producing the secretions (Slobodchikoff, unpublished). Similarly, if a beetle meets a number of predators and uses the defensive secretions often, it will quickly deplete its supply of water, Thus, it would be to the beetle's advantage to store the maximum amount of water possible, not only for its water balance, but also to produce defensive secretions. Expanding the storage capacity of the abdomen by shrinking the subelytral chamber would allow the beetle to maximize its water storage potential.

We would like to thank $\operatorname{Dr}$ C.S. Crawford for his helpful comments on this manuscript.

\section{REFERENCES}

Ahearn, G. A. (1970). The control of water loss in desert Tenebrionid beetles. F. exp. Biol. 53, 573-595. Ahearn, G. A. \& HAdley, N. F. (1969). The effects of temperature and humidity on water loss in two desert Tenebrionid beetles. Eleodes armata and Cryptoglossa verrucosa. Comp. Biachem. Physiol. 30, 739-749.

Cloudesley-Thompson, J. L. (1964). On the function of the sub-elytral cavity in desert Tenebrionidae. Entomalogist's Mon. Mag. roo, $148-157$.

NEY, E. B. (197I). The body temperature of Tenebrionid beetles in the Namib Desert of southern Africa. J. exp. Biol. 55, 253-272. 
Hadley, N. F. (1972). Desert species and adaptation. Am. Scient. 60, 338-347.

Riddle, W. A., Crawford, C. S. \& Zertong, A. M. (1976). Patterns of hemolymph osmoregulation in three desert arthropods. F. comp. Physiol. I12, 295-305.

TANNeR, V. M. \& PACKham, W. A. (I965). Tenebrionidae beetles of the Nevada test site. Brigham Young Univ. Sci. Bull., Biol. Ser. 6, I-44.

Tschinkre, W. R. (I975). A comparative study of the chemical defensive system of Tenebrionid beetles. Defensive behaviour and ancillary features. Ann. ent. Soc. Am. 68, 439-453. 